\title{
EFFECT OF SHORT FIBERS ORIENTATION ON MECHANICAL PROPERTIES OF COMPOSITE MATERIAL - FIBER REINFORCED CONCRETE
}

\author{
Vitalijs LUSIS ${ }^{\mathrm{a}, ~ c}$, Andrejs KRASNIKOVS ${ }^{\mathrm{a}}$, Olga KONONOVA ${ }^{\mathrm{a}}$, Videvuds-Arijs LAPSA ${ }^{\mathrm{c}}$, \\ Rimvydas STONYS ${ }^{\mathrm{b}}$, Arturs MACANOVSKIS ${ }^{\mathrm{a}}$, Arturs LUKASENOKS ${ }^{\mathrm{a}}$, c \\ anstitute of Mechanics, Riga Technical University, Ezermalas str. 6, LV-1006, Riga, Latvia \\ ${ }^{b}$ Scientific Institute of Thermal Insulation, Vilnius Gediminas Technical University, \\ Linkmenu g. 28, LT-08217, Vilnius, Lithuania \\ ${ }^{c}$ Institute of Building Production, Faculty of Civil Engineering, Riga Technical University, \\ Kipsalas St 6A/B, LV-1048, Riga, Latvia
}

Received 12 Apr 2017; accepted 04 Sep 2017

\begin{abstract}
Traditional fiberconcrete structures have fibres in the mix oriented in all spatial directions, distributed in the structural element volume homogenously, what not easy to obtain in practice. In many situations, structurally more effective is the insertion of fibres into the concrete structural element body by forming layers, with a predetermined fibre concentration and orientation in every layer. In the present investigation, layered fibre concrete is under investigation. Short steel fibres were attached to flexible warps with the necessary fibres concentration and orientation. Warps were placed into the prismatic mould separating them by concrete layers without fibres. Prisms were matured and tested under four-point bending. The bending-affected mechanical behaviour of cracked fibre concrete was simulated numerically by using a developed structural model. Comparing the simulation results with experimental data, material micromechanical fracture mechanisms were analysed and evaluated.
\end{abstract}

Keywords: fiber reinforced concrete, fibers orientation, fibers pull-out, oriented fiber distribution.

\section{Introduction}

Plain concrete is brittle; its tensile strength is much lower than compressive one. Short fibre is added to the concrete with the main goal to improve its internal tensile mechanical properties: strength, impact resistance, etc. Traditional fibre reinforced concrete consists of a concrete matrix with short fibres chaotically distributed over the material volume. Fibres are added to the concrete with other ingredients on the stage of mixing, after mixing FRC is filled into the mould and the concrete gradually hardens. Such FRC structure design, as well as the relevant scientific research, is based on two assumptions: first, fibres in the mix are oriented in all spatial directions with equal probability; secondly, fibres are distributed in the structural element volume homogenously. Respectively, FRC is macroscopically isotropic material. In reality, after the mixing process, several operations with the fresh FRC mix are carried out: pumping and transporting, pouring into a mould, while the others involve significant shear deformations leading to case sensitive non-uniform fibres distribution in the volume, having non-random fibres orientation (Ng et al. 2016; Bordelon, Roesler 2014; Ferrara et al. 2010, 2011; Ponikiewski et al. 2015; Krasņikovs et al. 2012). Non-predictable location and orientation of fibres (which are strongly dependent on mould filling process) invoke a large scatter in material strength and in the load-bearing structural elements. As regards structural elements designed mainly to work under bending load conditions, another approach is worth to be mentioned. It is possible to place a fibre fully predictably into the concrete structural element - beam or slab, forming reinforced layers (Lusis, Krasnikovs 2014). Another possibility is to reinforce concrete by arranging long fibres in layers parallel to each other. With such a material being placed under bending load, fibres are breaking up. In our case, the important difference observed when comparing with such a situation is the usage of short fibres. Short fibres are used with such a length that all of them are pulled out of the concrete during concrete cracking. Fibres geometry allows us to manage the pull-out process and to create material with strain softening or strain hardening behaviour during cracking as required. 
a)

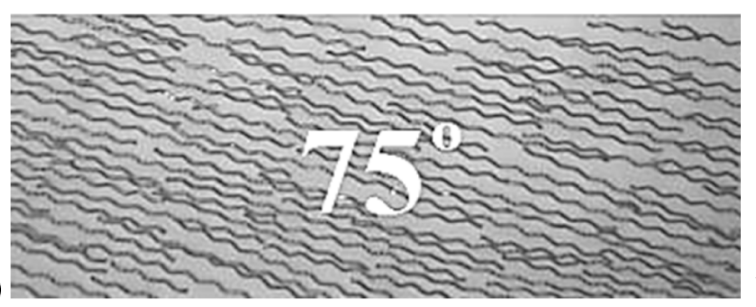

b)

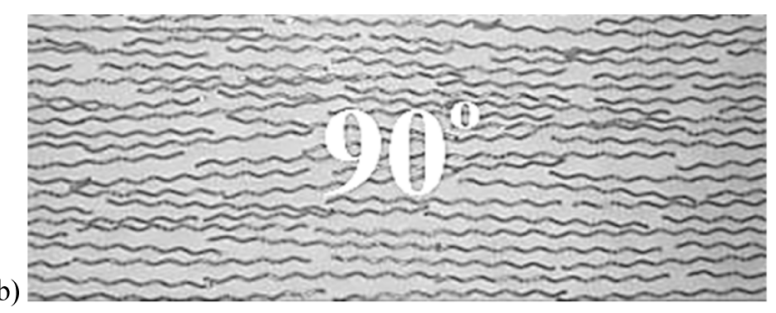

Fig. 1. Warps with attached sets of fibers oriented under the angle $75^{\circ}$ (a) and (b) $90^{\circ}$ to the prism longitudinal axis

The aim of this research is to create and investigate mechanical properties of steel fibre-reinforced (SFRC) concrete prisms with oriented fiber distribution inside. In this investigation, each concrete prism produced had been reinforced by prefabricated planar elements - flexible warps with the attached short steel fibres (SF). Each element had the necessary fibre concentration and orientation (see Fig. 1). Warps were placed into the prismatic mould being separated by concrete layers containing no fibres, thus, forming a layered "pie". Layered prisms were tested mechanically by bending, comparing the results with similar ones obtained for concrete prisms with chaotically distributed fibres and with numerical simulation predictions done when running the elaborated structural model.

\section{Experimental FRC samples fabrication}

Concrete ingredients (see Table 1) were placed into a concrete mixer where they were mixed without water and plasticizer in order to avoid any accumulation of particles of one fraction. Then water and plasticizer were added until liquid condition of the mix was reached. Short steel fibres were attached to the flexible warp. All specimens with fibres were made by using high strength concrete (HSC). Commercially available wavy SF Tabix + $1 / 60 \mathrm{~mm}$ : length $\mathrm{L}=60 \mathrm{~mm}$, wire diameter $\mathrm{d} 1 \mathrm{~mm}$, aspect ratio $1 / \mathrm{d}=60$, wave depth $0.40-0.65 \mathrm{~mm}$, wave length $8 \mathrm{~mm}$, tensile strength of drawn wire $1500 \mathrm{~N} / \mathrm{mm}^{2}$, were used in experiments (ArcelorMittal Bissen \& Bettembourg 2011). A polymer plastic net was used as a flexible warp. Each warp may have fibres oriented at some angle towards basic longitudinal direction (see Fig. 1). Beams

Table 1. Composition of SFRC with fibers of different types

\begin{tabular}{l|c|c}
\hline \multicolumn{1}{c|}{ Tables ingredients } & $\begin{array}{c}\text { Quantity, } \\
\mathrm{kg} / \mathrm{m}^{3}\end{array}$ & $\begin{array}{c}\text { Proportion } \\
\text { in mix }\end{array}$ \\
\hline Sand (fraction $0.3 / 2.5 \mathrm{~mm}$ ) & 469.5 & 0.71 \\
\hline Sand (fraction 0/1 mm) & 469.5 & 0.71 \\
\hline Dolomite flour & 187.8 & 0.29 \\
\hline Cement Cem I 42.5 N & 657.3 & 1 \\
\hline Silica fume Elkem 971 U & 93.9 & 0.14 \\
\hline Water $\mathrm{H}_{2} \mathrm{O}$ & 238.7 & 0.36 \\
\hline Plasticizer & 6.6 & 0.01 \\
\hline Fibers, steel & 54.4 & \\
\hline
\end{tabular}

were made in moulds. Warps with fibres were placed into the prismatic mould separating them by concrete layers without fibres. Compressive cube tests were conducted to determine the concrete compressive strength. The obtained concrete strength, according to the average value of the test results including eight specimen data, was 87.3 MPa, which corresponds to the concrete strength class $\mathrm{C} 70 / 85$.

SFRC research of prisms with dimensions of $100 \times 100 \times 400 \mathrm{~mm}$ was carried out. Prisms were fabricated, matured and tested under four-point bending for evaluating mechanical and fracture properties of SFRC under the crack propagation mode. Comparative analysis of three and four-point bending mechanical testing of fiberconcrete beams can be found in Bencardino et al. (2013). Four-point bending is recommended by AFGCSETRA, DAfStB, GOST, ASTM (AFGC-SETRA 2002; DAfStB 2003; GOST 10180-2012 2012; ASTM C1399/ C1399M 2015). Tree-point bending in many situations is associated with the formation of a notch when sowing the bottom part of the prism, which is not convenient in our case (for prisms, the main load-bearing reinforcement would be cut). The prisms testing scheme is shown in Figure 2. Two HBM WA20 LVDTs sensors installed on both sides of each prism recorded the midpoint of vertical deflection of the prism during the tests. For load application control, the load frame of Automax 5 loading machine was used. Loading rate was $0.25 \mathrm{kN}$ per minute.

The load vs. vertical deflection curve $\mathrm{F}-\Delta(\Delta-$ vertical deflection of the prism midpoint) was obtained in every experiment (with respect to the middle of a span). Sensors were connected to the data acquisition unit and the computer where the obtained data was recorded and available after experiments. In process of loading, a macro-crack on the bottom part of the prism started to

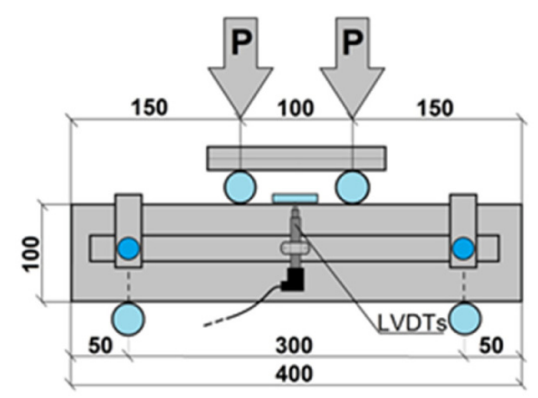

Fig. 2. 4PBT scheme 
take shape. The crack is growing, reaching $0.7-0.8$ of the prism thickness (if the crack opening displacement (COD) is less than $6-8 \mathrm{~mm}$ ). Fibres are bridging the crack and are slowly pulling out of the crack flanks. A simple geometrical evaluation shows that the crack opening displacement is in a good correlation with the prism midpoint vertical displacement $\Delta$. The characteristics of the material are determined by this test; moreover, the equivalent flexural tensile strength can be obtained based on that data.

In total, 72 warps with attached fibres were prepared, with the fibres incorporated at a specific degree angle; four warps were incorporated in each specimen. Consequently, there were 140 fibres on each warp. 24 warps were with fibres oriented at an angle $90^{\circ}$ in relation to the expected direction of the macro-crack (fibres are aligned along the prism's longitudinal axes direction), 24 warps were with fibres oriented at an angle $75^{\circ}$ in relation to the expected direction of the macro-crack. In addition, 24 warps without fibres were prepared. Fibres were incorporated into the warp in such a way that two adjacent fibres lying along at the ends of one line were at the middle of the neighbouring fibre lying along the adjacent line in the warp (see Fig. 1). The warps with fibres were incorporated into prisms in four different ways/groups. Each group consisted of six specimens; 24 specimens with SF were prepared in total.

\section{Distribution and concentration of fibers in the specimens}

Specimen Group 1 - traditionally prepared SFRC. $60 \mathrm{~mm}$-long wavy fibres with concentration $54.4 \mathrm{~kg} / \mathrm{m}^{3}$ were added to the concrete mix. SF has random locations and orientations in the concrete matrix (it was supposed that fibres were homogeneously distributed over the volume of each specimen - the classic method).

Since the experiment had to find out if the "catch" without fibres affects the overall results, Group 2 was established which was similar to SFRC specimens produced by using traditional methods and adding $60 \mathrm{~mm}$ long wavy fibres with similar concentration $54.4 \mathrm{~kg} / \mathrm{m}^{3}$ to the concrete mix. This time however, warps without fibres were incorporated in four layers of fibre concrete distanced at $5 \mathrm{~mm}$ from each other (see Fig. 3).

The production of specimens included the following steps:

1. Concrete mix was poured into a mould up to $5 \mathrm{~mm}$;

2. A warp was put into the mould on the first layer of concrete mix; Steps 1 and 2 were repeated 3 times so that the warp without fibres is encountered in every $5 \mathrm{~mm}$ of the structure, namely $-5 \mathrm{~mm}, 10 \mathrm{~mm}$, $15 \mathrm{~mm}$ and $20 \mathrm{~mm}$ from the base of the mould (see Fig. 3);

3. The mould was filled with concrete to the brim, reaching $100 \mathrm{~mm}$ respectively.

The maximum fibre content in the prepared beams was concentrated at the bottom side of the beam. For

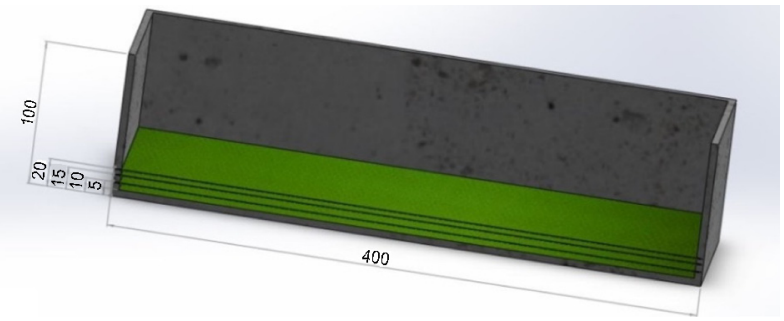

Fig. 3. Group 2 specimens scheme (four warps without fibers are in the specimen)

Groups 3 and 4, warps with oriented fibres were incorporated in the FRC beams in four layers.

In Group 2, SF is assumed to have random locations and orientations in the concrete matrix; they are homogeneously distributed over the entire volume of each specimen. Each specimen had four incorporated warps without fibres.

In Group 3, specimens constituting $1 / 4$ of the total amount of $60 \mathrm{~mm}$-long wavy fibres $\left(54.4 \mathrm{~kg} / \mathrm{m}^{3}\right)$ were introduced in each warp. Fibres were oriented at an angle $75^{\circ}$ with respect to the potential macro-crack direction, or, $25^{\circ}$ in relation to the longitudinal axis of the prism. Four warps separated by $5 \mathrm{~mm}$-thick concrete layers without fibres were placed in the mould and were covered with $80 \mathrm{~mm}$ of concrete without fibres (see Fig. 4).

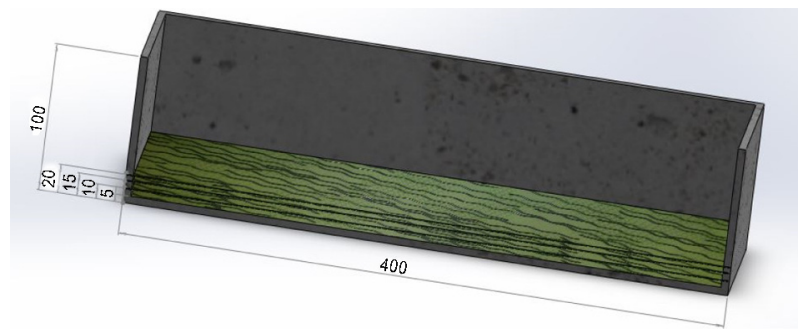

Fig. 4. Group 3 specimens scheme (is shown warps location and fibers orientation in them, in the specimen)

In Group 4 specimens, $1 / 4$ of the total amount of fibres $\left(54.4 \mathrm{~kg} / \mathrm{m}^{3}\right)$ was introduced into each warp. Fibres were oriented at an angle $90^{\circ}$ to the potential macrocrack direction or $0^{\circ}$ in relation to the longitudinal axis of the prism. Four warps separated by $5 \mathrm{~mm}$-thick concrete layers without fibres were stacked in the mould and were covered with $80 \mathrm{~mm}$ of concrete without fibres (see Fig. 5).

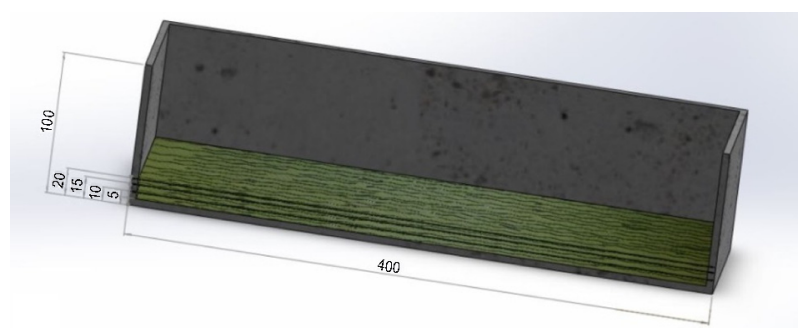

Fig. 5. Group 4 specimens scheme (is shown warps location and fibers orientation in them, in the specimen) 

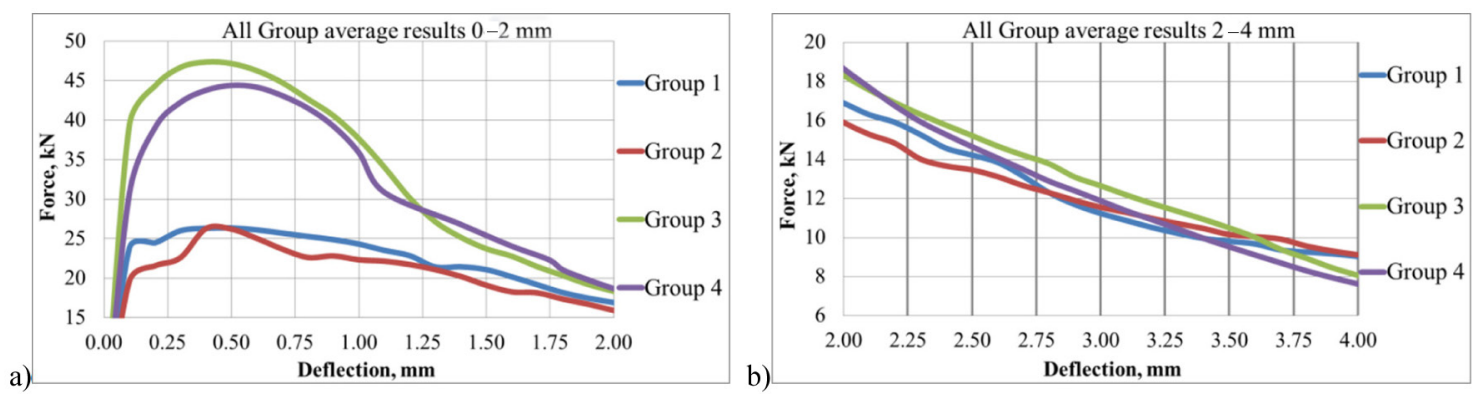

Fig. 6. Comparison of the average deflection results in all Groups $0-2 \mathrm{~mm}$ (a) and 2-4 $\mathrm{mm}$ (b)

\section{Experimental results and discussion}

Prepared prisms were tested under four-point bending. The testing results related to Groups 3 and 4 were compared with prisms having homogeneously distributed fibres of Groups 1 and 2. Force-deflection average curves of the 4PBT are shown in Figure 6 (a) with regard to 0-2 $\mathrm{mm}$ deflection and in Figure 6 (b) with regard to 2-4 mm deflection.

When deflection is within the range of $0-2 \mathrm{~mm}$ (which corresponds to COD equal to the same value), Group 3 and Group 4 specimens show similar results which are significantly higher than those referred to Group 1 and 2 (reference specimens). Samples with warps show much higher load-bearing capacity as compared to samples having chaotically distributed fibres within the prism volume. In the cross section of the macro-crack, more fibres are bearing load in Groups 3 and 4 as against those of Groups 1 and 2. More energy is necessary to separate them from concrete and start to pull them out. The volume damage includes more cracks (fragmentation of concrete around wraps), which can be viewed in Figure 7. At the beginning, Group 1 is by $7-10 \%$ higher as compared to the results of Group 2, which can be explained by the random orientation of 2D-fibre in the vicinity of warps incorporating them without fibres in Group 1 specimens. Group 3 (fibre orientation in the specimen at angle $\pm 75^{\circ}$ ) and Group 4 (fibre orientation in the specimen at angle $90^{\circ}$ ) show very similar results. It looks like the angle of fibres does not significantly affect the results if their length is sufficient in relation to the direction of crack formation. The reason may be a quite high fibre concentration on the warps, and the warps close location to each other. The warps are working as a reinforcing layer and no fiber pull-out mechanism works.

Three stages of each curve can be seen: the first one is the linear elastic (deflection from $0 \mathrm{~mm}$ to $0.01 \mathrm{~mm}$ ). At this stage, the FRC prisms become deformed without a visible crack opening. At this stage, concrete micro cracks accumulate and grow, forming a network of cracks. The macro crack is shaped perpendicularly to the longitudinal axis of a prism. The density of the crack network depends on the specimen's geometry, size of fibres, and their amount. Fibres traversing the macro cracks begin to bear load, while the cracks are still invisible on the outer surface of the specimen.
It proceeds in the following way: load-bearing fibres detach from the concrete and start pulling out from one or both ends. The individual load-carrying capacity of fibre depends on its orientation towards the crack plane and on how far it is extracted. The next stage begins with a deviation of curves from the straight line and it terminates when reaching the maximum value on the curve, with the deflection of prisms equal to $0.1-1 \mathrm{~mm}$ (see Fig. 6). In Groups 1 and 2, the scatter in results is more considerable (a greater confidence interval) than in Groups 3 and 4.

It can be explained by the fact that fibres were incorporated in these specimens with the traditional method; therefore fibre concentration and their distribution in the specimens is non-homogenous affecting the results. Although the results for $0.5-3.5 \mathrm{~mm}$ differ, a common trend can be observed: in groups with oriented fibres more energy is needed in crack opening stage than in Groups 1 and 2. In Groups 1 and 2 load bearing mechanisms is - fibres are individually pulling out of concrete and are bearing load; In Groups 3 and 4 are pulling out layers with high concrete fragmentation in reinforced by fibres layers. It's obvious to conclude: more effective result will

a)

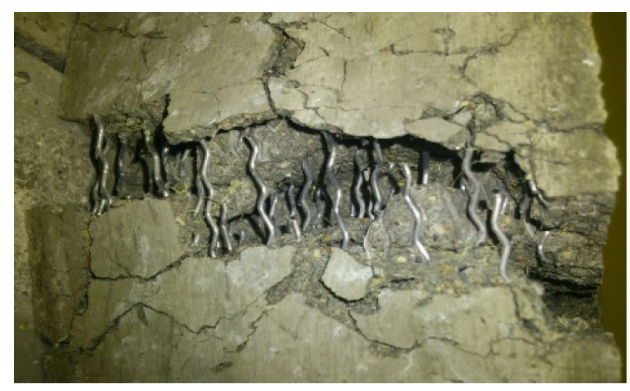

b)

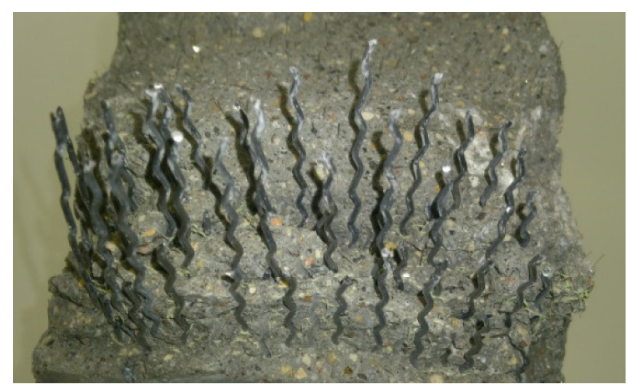

Fig. 7. a) Group 4 sample (bottom part) during macro-crack opening; b) after total failure 

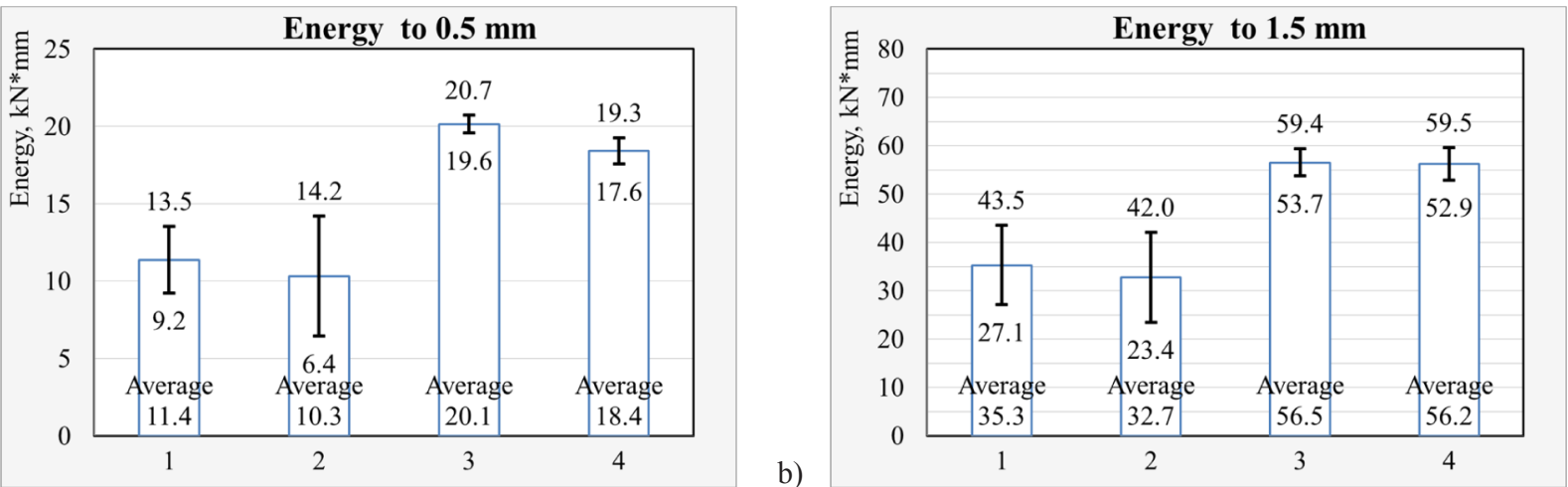

Fig. 8. Energy spent reaching deflection equal to $0.5 \mathrm{~mm}$ (a), and $1.5 \mathrm{~mm}$ (b)
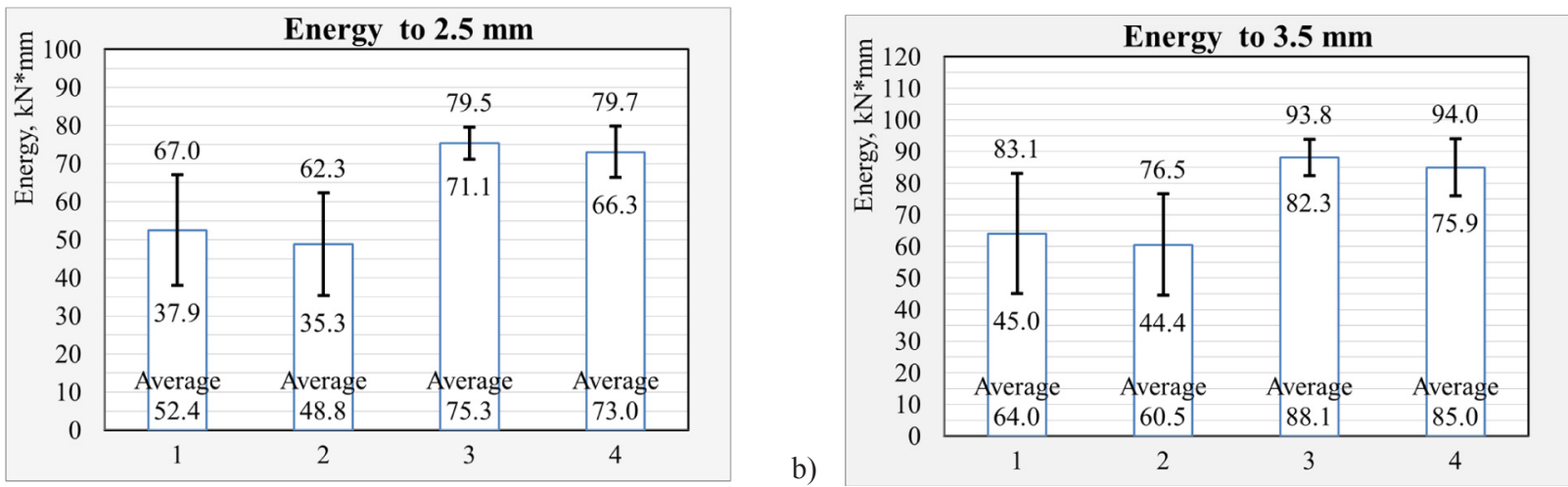

Fig. 9. Energy spent reaching deflection equal to $2.5 \mathrm{~mm}$ (a), and $3.5 \mathrm{~mm}$ (b)

be obtained with warps having less fibres concentration when every fiber in warp will be able to realize its pullout mechanisms.

The third stage is characterized by decline of the total load carrying capacity of fiber. The capacity decreases proportionally to the size of the crack opening. Large amount of fibres leads to overload of the concrete matrix which leads to spalling of the concrete. It can be observed that Group 2 reaches a lower average load carrying capacity in the third stage (macro cracks) compared to the specimens with the non-homogeneous distribution of fibres.

Figures 8 and 9 show the comparison of deformation energy spent by loading samples of all groups at COD reaching values as follows: $0.5 \mathrm{~mm} ; 1.5 \mathrm{~mm} ; 2.5 \mathrm{~mm}$ and $3.5 \mathrm{~mm}$. In the diagrams in Figures 10-11, the average percentage of energy spent by different groups if Group 1 is assumed to constitute $100 \%$ is shown. We can see that, at the beginning, part of cracking for respective specimens in Groups 4 and 3 is required to spend from $61.8 \%$ to $77.0 \%$ more energy initiating macro-crack opening process. The highest results were obtained for specimens from Group 3.

When macro-crack COD is increasing (COD egual to $2.5 \mathrm{~mm}$ and $3.5 \mathrm{~mm}$ ), energy balance between groups is changing. a)
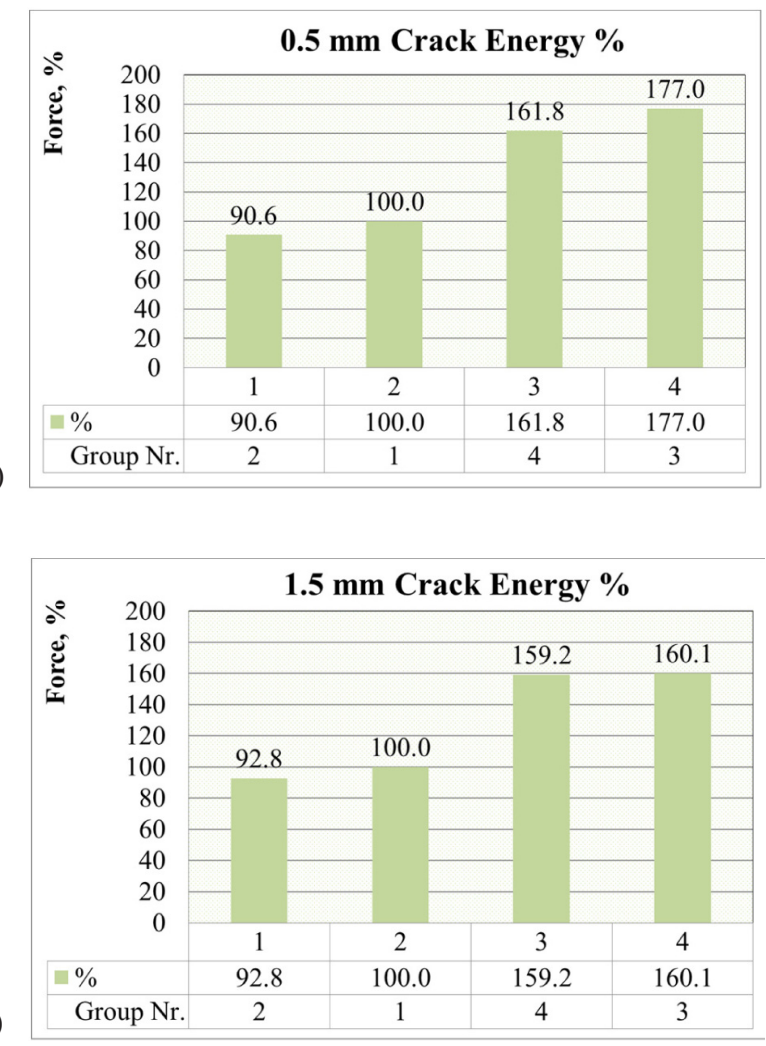

Fig. 10. Energy spent reaching COD equal to $0.5 \mathrm{~mm}$ (a), and $1.5 \mathrm{~mm}$ (b), Group 1 is designated as $100 \%$ 
a)

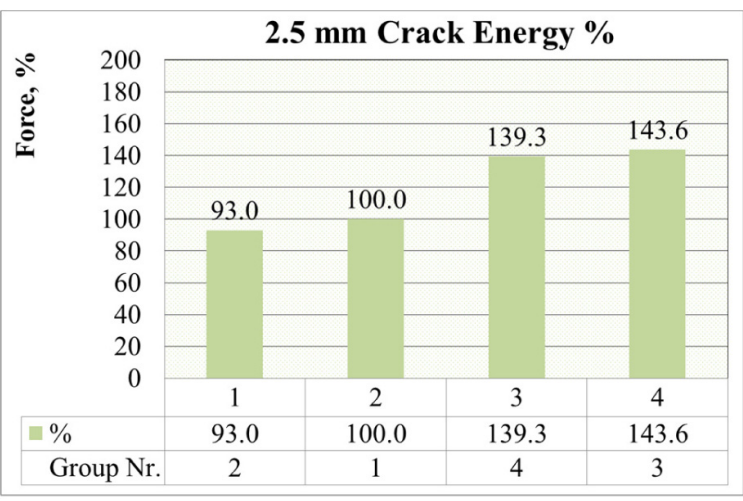

b)

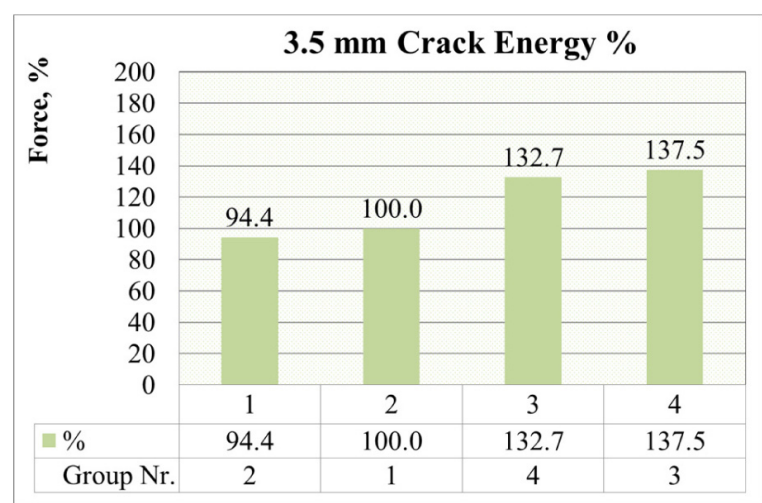

Fig. 11. Energy spent reaching COD equal to $2.5 \mathrm{~mm}(\mathrm{a})$, and $3.5 \mathrm{~mm}$ (b), Group 1 is designated as $100 \%$

Individual fibres pull-out mechanisms is becoming more energy expensive as against the layers of pull-out mechanisms realized in samples of Groups 3 and 4. A significant increase in tensile strength and compressive strength is the most important SFRC property. These improved properties stem from the fiber efficiency in controlling crack widths that is based on the individual fibre performance. Group 1 and 2 specimens showed a lower load-bearing capacity in the cracking stage as compared to the specimens with oriented fibres distributed within the volume of specimens. The oriented fibres were incorporated into the concrete specimens in two different ways for Groups 3 and 4. Among the testing results, Groups 3 and 4 with oriented fibres distributed in the lower $20 \mathrm{~mm}$ of the specimens showed the most significant difference as compared to the standard specimens in Group 2. Namely, the load bearing capacity was by $61.8-77 \%$ higher than that of the specimens where fibres were incorporated by the traditional method.

The testing results of Groups 1 and 2, where traditional methods were used for SFRC, are characterised by rather scattered results that are necessary for designing buildings as fibres were always randomly distributed.

Figure 7 (b) shows the failure surface in order to find out whether the fibres are incorporated according to the predefined parameters. It was demonstrated by the experiments that in the situations where fibres are at an angle in relation to the pull-out force applied, the importance of particle congestion is higher in comparison with the other non-linear processes - friction and plastic deformation. Interaction of fibres is also important because high volume of fibres usually invokes a start-up of new micromechanical mechanisms; fibres are working together and are not pulling out individually, with the stress concentration resulting in crumbling of the concrete matrix and decreased load-bearing capacity of the FRC structure.

The results obtained from these tests were critically assessed, and it obvious that fibres contribute immensely to the structural integrity. Although the same concrete mixture and volume of fibres were used for the set of beams, the post-cracking behaviour significantly differs. As expected, the post-cracking capacity became higher with the increasing amount of fibres. The results were mainly influenced by the orientation and number of fibres acting at the crack section. When examining the experimental data it is easy to conclude that prisms with organized oriented fibres distribution, when all fibers in a ply are oriented at the same angle (angles $75^{\circ}$ or $90^{\circ}$ ) and such a ply (or plies) is located in the stretched part of the beam, have a higher load bearing capacity as compared to the beams having the same amount of fibers distributed uniformly in the prism volume. Fibers concentration in every warp was too big. An individual fibre load bearing mechanical mechanism works poorly. It may be expected that, if fibres concentration were lower, the individual fibres pull-out micro-mechanisms would work better and would have a higher effect. The research revealed that SF can increase the bending resistance of concrete structural element significantly when SF are optimally oriented and placed, thus ensuring the predictability of the cracking process and the structure affected by the risk of cracking as well as possibilities to control the crack opening process.

\section{SFRC cracking process numerical modelling}

Finite element method (FEM) approach was used calculating a single fibre pull out mechanical process. The mechanical behaviour of such a material depends on the amount, orientation and spatial distribution of fibres and the particular fibre geometry, as well as design of the cementitious matrix mix and the way of concrete mix placement into the mould (Swamy, Mangat 1974; Yazici et al. 2007; Bencardino 2013; Bencardino et al. 2008, 2013; Kurihara et al. 2000; Barros, Cruz 2001). Structural models simulated SFRC prisms mechanical behaviour under bending were observed in Pupurs (2011), Li and Mobasher (1998), Prudencio et al. (2007) and Jones et al. (2007). Pull-out tests with different fibres were performed and reported in Pupurs (2011), Robins et al. (2002), Krasnikovs and Kononova (2009) and $\mathrm{Ng}$ et al. (2010).

A model was developed suitable for estimating the load-bearing capacity of FRC beam subject to bending (Pupurs 2011). The macro-scale model can be briefly explained as follows: previously experimentally obtained pull-out curves (force-pulled out distance) for all undulat- 
ed fibre embedment lengths and inclination angles were stored in a database file. It is supposed that a macro-crack will occur within the area between the two upper supports where the bending moment is constant and maximal. Crack surface is expected to occur at the cross-section with minimal number of fibres crossing it. In the case of uniform in volume fibres distribution (sample Group 1 and 2), Monte-Carlo simulations were used to obtain each particular fibre location within a concrete sample. A random distribution function was applied to assign the location and orientation angle to each fibre inside a concrete prism. Each fibre geometrical centre and spatial orientation angles were obtained in a single Monte-Carlo simulation run. The weakest cross section (place where macro-crack will be formed) was recognized as the cross section with the smallest amount of fibres crossing it. If it is known where the weakest cross section is located, the number, location and spatial orientation of each fibre within the weakest cross-section is known as well as the orientation to macro-crack plane. If a crack is opening under load increase, it is suggested that the shortest fibre end will start to pull out. The crack starts to open (this procedure in the model proceeds step by step, increasing crack mouth opening displacement (CMOD)). At every step (known value of CMOD) every fibre which is crossing the crack is pulling out and is bearing load. The load value corresponding to the current CMOD magnitude is numerically obtained from pull-out experimental data file created earlier. Information about the location, orientation, type, and embedment length of each fibre is known previously from the distribution procedure and is kept in the model. Then the corresponding data from the database file which contains all information obtained by pull out experiments must be correctly read and applied. This modelling approach enabling one to assess the type of fibres, their amount and distribution in the FRC allows one to obtain cost effective design solutions as well as more realistic behaviour models of the FRC structures. Modelling results were compared with the experimental data. Figure $12(\mathrm{a}, \mathrm{b}, \mathrm{c})$ shows the average experimental curve in comparison to the results of numeric modelling for specimens of Group 1, 3, 4.

Analysis of the obtained results (curves) show that the modelling results are approximately close to the experimental results, thus confirming accuracy and reliability of the modelling in the case of samples 1 . At the same time, attempts to get the idea of model samples mechanical behaviour under bending with respect to Group 3 and Group 4 have shown deviation from experimental data, especially at the beginning of force-CMOD curve. The explanation is that single fibre pull-out micromechanical mechanisms are not working. Fibres in warps covered by concrete are functioning as layers.

\section{Conclusions}

The research on load-bearing capacity of non-homogenous FRC under the bending load has been done com-

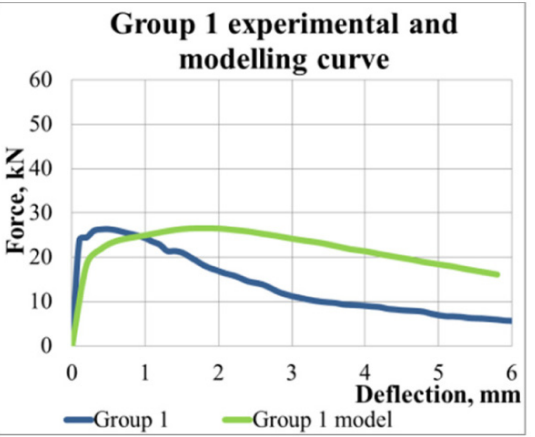

a)

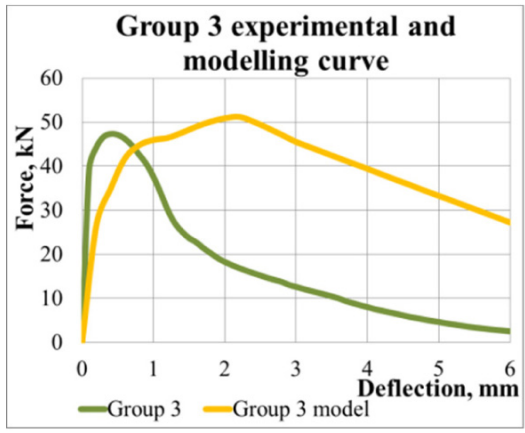

b)

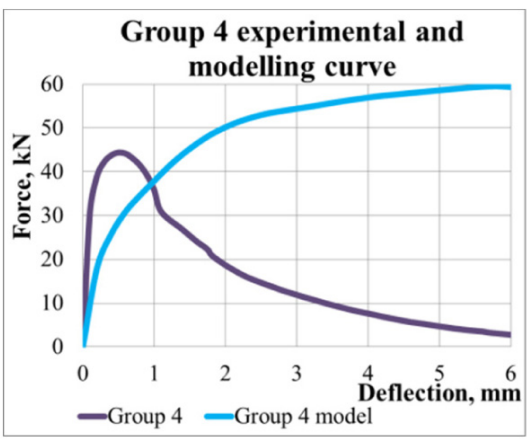

c)

Fig. 12. The average experimental result and modelling curve for Group 1 (a); Group 3 (b); Group 4 (c)

paring it with load-bearing capacity of the homogenous FRC. The possibility to create SFRC prisms by using prefabricated flexible warps with attached short fibres was investigated both experimentally and numerically, incorporating warps in the tensile zone of a structure with maximum tensile stresses, with the same amount of fibres in homogenous and non-homogenous SFRC. The higher flexural load bearing results were obtained at the beginning of load-CMOD curve.

A numeric model was developed for estimating the load-bearing capacity in the cracking and crack-opening stage of the homogenous FRC elements with chaotic fibres distribution. It was shown by comparing numerical modelling results with experimental data that the micromechanical mechanisms of a single fibre pull-out are not working under the situation of non-homogenous FRC at the cracking stage. Fibres in warps covered by concrete are working as layers. Moreover, at the beginning layers separate from each other. 
After the experiments and analysis of the obtained information we can state with assurance that by using the latest SFRC technologies - orienting and dividing fibres into certain layers - it is possible to have the desired effect, namely, the fibre orientation and distribution have significant impact on SFRC tensile strength.

At the beginning part of cracking for respective specimens in Groups 3 and 4 (with non-homogeneous fibres distribution in samples), more energy initiating macro-crack opening process is required. The highest results were obtained for specimens from Group 3.

When macro-crack COD is increasing (COD equal to $2.5 \mathrm{~mm}$ and $3.5 \mathrm{~mm}$ ), energy balance between groups is changing.

Individual fibres pull-out mechanisms are becoming more energy expensive as compared to layer pullout mechanisms realized in samples of Groups 3 and 4. Group 1 and 2 specimens showed a lower load bearing capacity at the cracking stage as compared to the specimens with oriented fibres distributed in the volume of specimens. Oriented fibres were incorporated into the concrete specimens in two different ways for Groups 3 and 4 . In the testing results, Groups 3 and 4 with oriented fibres distributed in the lower $20 \mathrm{~mm}$ of the specimens showed the most significant difference as compared to the standard specimens in Group 2, and a higher load bearing capacity than the specimens where fibres were incorporated by the traditional method.

\section{Acknowledgements}

Support for this work was provided by the Riga Technical University through the Scientific Research Project Competition for Young Researchers No. ZP-2016/11.

\section{References}

AFGC-SETRA. 2002. AFGC-SETRA ultra high performance fibre-reinforced concretes. Interim recommendations.

ArcelorMittal Bissen \& Bettembourg. 2011. Technical data sheet: Tabix $+1 / 60$.

ASTM C1399 / C1399M. Standard test method for obtaining average residual-strength of fiber-reinforced concrete. ASTM, 2015.

Barros, J. A. O.; Cruz, J. S. 2001. Fracture energy of steel fiberreinforced concrete, Mechanics of Composite Materials and Structures 8: 29-45. https://doi.org/10.1080/107594101459815

Bencardino, F. 2013. Mechanical parameters and post-cracking behaviour of HPFRC according to three-point and fourpoint bending test, Advances in Civil Engineering 2013, Article ID 179712. 9 p.

Bencardino, F.; Rizzuti, L.; Spadea, G.; Swamy, R. N. 2008. Stress-strain behavior of steel fiber-reinforced concrete in compression, Journal of Materials in Civil Engineering 20(3): 255-263.

https://doi.org/10.1061/(ASCE)0899-1561(2008)20:3(255)

Bencardino, F.; Rizzuti, L.; Spadea, G.; Swamy, R. N. 2013. Implications of test methodology on post-cracking and fracture behaviour of steel fibre reinforced concrete, Composites Part B: Engineering 46: 31-38. https://doi.org/10.1016/j.compositesb.2012.10.016
Bordelon, A. C.; Roesler, J. R. 2014. Spatial distribution of synthetic fibers in concrete with X-ray computed tomography, Cement and Concrete Composites 53: 35-43. https://doi.org/10.1016/j.cemconcomp.2014.04.007

DAfStB. 2003. Richtlinie Stahlfaserbeton [Technical guidelines for steel fiber reinforces concrete], part 1-4. Deutscher Ausschuss für Stahlbeton im DIN [German Association for Reinforced Concrete within DIN]. Berlin.

Ferrara, L.; Ozyurt, N.; Prisco, M. 2010. High mechanical performance of fibre reinforced cementitious composites: the role of "casting-flow induced" fibre orientation, Materials and Structures 44(1): 109-128. https://doi.org/10.1617/s11527-010-9613-9

Ferrara, L.; Ozyurt, N.; Di Prisco, M. 2011. High mechanical performance of fibre reinforced cementitious composites: The role of "casting-flow induced" fibre orientation, Materials and Structures 44(1): 109-128. https://doi.org/10.1617/s11527-010-9613-9

GOST 10180-2012. Concretes, strenght evaluatiom methods based on control samples. 2012.

Jones, P. A.; Austin, S. A.; Robins, P. J. 2007. Predicting the flexural load-deflection response of steel fibre reinforced concrete from strain, crack-width, fibre pull-out and distribution data, Materials and Structures 41(3): 449-463. https://doi.org/10.1617/s11527-007-9327-9

Krasnikovs, A.; Kononova, O. 2009. Strength prediction for concrete reinforced by different length and shape short steel fibers, Mechanics 31: 89-93.

Krasņikovs, A.; Mačanovskis, A.; Lūsis, V.; Lapsa, V.-Ā.; Zaharevskis, V.; Mačanovskis, E. 2012. Short fibers distribution investigation in fiber concrete, Mechanics 1: 54-62.

Kurihara, N.; Kunieda, M.; Kamada, T.; Uchida, Y.; Rokugo, K. 2000. Tension softening diagrams and evaluation of properties of steel fiber reinforced concrete, Engineering Fracture Mechanics 65(2-3): 235-245. https://doi.org/10.1016/S0013-7944(99)00116-2

Li, C. Y.; Mobasher, B. 1998. Finite element simulations of fiber pullout toughening in fiber reinforced cement based composites, Advanced Cement Based Materials 7(3-4): 123-132. https://doi.org/10.1016/S1065-7355(97)00087-4

Lusis, V.; Krasnikovs, A. 2014. Non-homogeneous layered fiber reinforced concrete, International Journal of Civil, Architectural Science and Engineering 8(4): 92-97.

Ng, T.; Htut, T. N. S.; Foster, S. J. 2010. Mode I and II fracture behaviour of steel fibre reinforced high strength geopolymer concrete: an experimental investigation, in Fracture mechanics of concrete and concrete structures - high performance, fiber reinforced concrete, special loadings and structural applications. Korea Concrete Institute, Korea, $1504-1511$.

Ng, T. S.; Htut, T. N. S.; Foster, S. J. 2016. Steel fibre reinforced concrete: From X-ray imaging observation to modelling, in The Second International Conference on Science, Engineering \& Environment, 2016, Osaka, Japan: CRC Press, 407-414.

Ponikiewski, T.; Gołaszewski, J.; Rudzki, M.; Bugdolb, M. 2015. Determination of steel fibres distribution in self-compacting concrete beams using X-ray computed tomography, Archives of Civil and Mechanical Engineering 15(2): 558568. https://doi.org/10.1016/j.acme.2014.08.008

Prudencio, Jr. L.; Austin, S.; Jones, P.; Armelin, H.; Robins, P. 2007. Prediction of steel fibre reinforced concrete under flexure from an inferred fibre pull-out response, Materials and Structures 39(6): 601-610. https://doi.org/10.1617/s11527-006-9091-2

Pupurs, A. 2011. Prediction of load bearing capacity of structural steel fiber reinforced concrete. Riga: Riga Technical University. 
Robins, P.; Austin, S.; Jones, P. 2002. Pull-out behaviour of hooked steel fibres, Materials and Structures 35: 434-442. https://doi.org/10.1007/BF02483148

Swamy, R. N.; Mangat, P. S. 1974. Influence of fiber geometry on the properties of steel fiber reinforced concrete, Cement and Concrete Research 4(3): 451-465. https://doi.org/10.1016/0008-8846(74)90110-0
Yazici, Ş.; Inan, G.; Tabak, V. 2007. Effect of aspect ratio and volume fraction of steel fiber on the mechanical properties of SFRC, Construction and Building Materials 21: 1250 1253. https://doi.org/10.1016/j.conbuildmat.2006.05.025

Vitalijs LUSIS. Dr Sc. Ing. (PhD) in Mechanics received in 2015. He is Associate Professor at Riga Technical University. His research interests include fracture mechanics of fiber-reinforced concrete, durability of high performance concrete, innovation fiberreinforced concrete technologies. V.Lusis is an author and co-author of 20 scientific publications and 9 patents for invention. Since 2011 he is member of Latvian Concrete Association and Latvian Materials Research Society.

Andrejs KRASNIKOVS. Professor, Academic of the Latvian Academy of Sciences. Dr Sc. Ing. (PhD) in Mathematics and Physics received in 1986. Head of Concrete Mechanics Laboratory since 2000, professor since 2006. Visiting professor of Virginia Tech (US) (2000); visiting researcher of Lulea Tech (Sweden) (2002). Academic fields of interest: materials mechanics, composite materials, nano-materials, concretes, asphalts, experimental mechanics and numerical investigations. Author of more than 180 scientific publications and 25 invention patents. During the last five years, RTU contractor and tasks leader in three large international and more than ten regional scientific research projects.

Olga KONONOVA. Dr Sc. Ing. (PhD) in Mechanics received in 2005, RTU professor since 2012. Fields of interest; material mechanics, composite materials, concretes, experimental investigations and numerical modelling. Author of more than 100 scientific publications and 7 invention patents. Participant of four EU research projects and leader of seven domestic research projects.

Videvuds-Arijs LAPSA Dr Sc. Ing. (PhD). Assoc. professor Institute of Building production, Faculty of Civil Engineering, RTU. His research interests include fracture mechanics of fiber-reinforced concrete, durability of high performance concrete, extrusion technology, innovation fiber-reinforced concrete technologies. V-A. Lapsa is an author and co-author of 100 scientific publications, 100 patents for invention. He is member of Latvian Concrete Association and Latvian Materials Research Society.

Rimvydas STONYS. Dr, Senior Researcher, Laboratory of Building Products Technology, Scientific Institute of Thermal Insulation of Vilnius Gediminas Technical University, Lithuania. Research interests: materials science, application of nanotechnologies in cementitious materials, refractory concretes and their application.

Arturs MACANOVSKIS. Dr Sc. Ing. (PhD) in Mechanics received in 2014, Riga Technical University, Institute of Mechanics, A. Macanovskis is an author and co-author of 20 scientific publications, 3 patents of invention. Takes active part in various scientific conferences (over 20 presentations) associated with composite materials. Has been studying fiber-reinforced concrete structure with various fibers types (metal, polymer, etc.).

Arturs LUKASENOKS. PhD student, Faculty of Civil engineering, Concrete Mechanics Laboratory, RTU. A. Lukasenoks is an author and co-author of 5 scientific publications. Has been studying fiberconcrete structure with various fibers types. 